\title{
O ONTEM, O HOJE E O AMANHÃ DOS ESTUDOS SOBRE AGRONEGÓCIO: UMA ANÁLISE BIBLIOMÉTRICA DE 1945 A 2020
}

\author{
Yesterday, Today and Tomorrow of Studies on Agribusiness: A Bibliometric Analysis From 1945 To 2020
}

\section{RESUMO}

O agronegócio, importante setor da economia, tem despertado o interesse da academia, implicando em uma gama de produções científicas que podem gerar conhecimento para o campo das ciências agrárias e diversas outras áreas. Este estudo teve como objetivo investigar o comportamento da literatura científica internacional sobre o agronegócio, a fim de poder pautar os temas que estão emergindo. Para tanto, utilizou-se da técnica de análise de dados bibliométrica, conduzida em uma das principais bases indexadoras, a Web of Science (WoS), por meio dos softwares EndNote e CiteSpace. Fez-se uma revisão da literatura, identificando 787 trabalhos publicados entre os anos de 1945 a 2020. Constatou-se crescimento significativo na produção acadêmica em torno da pauta do agronegócio. A partir de 2007, Brasil e Estados Unidos (EUA) foram os países com maior quantidade de publicações sobre o tema, com destaque para a maior diversidade de periódicos que publicaram sobre o tema. Cada vez mais o agronegócio vem sendo estudado de maneira transdisciplinar, com pluralidade de temas atrelados a ele, tais como inovação, performance, administração estratégica, desenvolvimento e sustentabilidade. O desenvolvimento econômico e ambiental, pautado por tópicos de sustentabilidade, das suas mais variadas matrizes, vêm ascendendo consideravelmente. Concluiu-se que pesquisas sobre o agronegócio se encontram em expansão, em diferentes áreas do conhecimento, permitindo compreender que tal conceito, sustentado pela imagem de rede, está cada vez menos condicionado à agricultura de maneira isolada, e sim à sua cadeia produtiva. $\mathrm{O}$ artigo ainda conta com uma figura que resume a agenda de estudos futuros.

Ana Luíza Cordeiro Pereira

Universidade Federal de Lavras

analuizacordeiro96@gmail.com

Rafael Rodolfo Sartorelli Sadocco

Universidade Federal de Lavras

rafael.sadocco@gmail.com

Marcos Giovane da Silva

Universidade Federal de Lavras

marcosufsj21@gmail.com

Marcelo Oliveira Júnior

Universidade Federal de Lavras

marcelooli333@gmail.com

Leandro Carvalho Bassotto

Universidade Federal de Lavras

bassotto.lc@gmail.com

Recebido em: 14/12/2020. Aprovado em: 14/05/2021.

Avaliado pelo sistema double blind review

Avaliador científico: Daniel Leite Mesquita

DOI: $10.48142 / 2320211737$

\begin{abstract}
Agribusiness, an important sector of the economy, has aroused the academic interest, implying a range of scientific productions that can generate knowledge for the field of agricultural sciences and several other. This study aimed to investigate the behavior of international scientific literature on agribusiness, in order to be able to guide the themes that are emerging within the segment. For that, we used the technique of bibliometric data analysis, conducted in one of the main indexing bases in the world, the Web of Science (WoS), through the software EndNote and CiteSpace. A literature review was carried out, identifying 787 works published between the years 1945 to 2020. There was a significant growth in academic production around the agribusiness agenda. As of 2007, Brazil and the United States (USA) were the countries with the largest number of publications on the subject, with emphasis on the greater diversity of journals. It was perceived that agribusiness are being more studied in a transdisciplinary way, with a plurality of themes, such as innovation, performance, strategic management, development and sustainability. Economic and environmental development, oriented by topics of sustainability, of its most varied matrices and possibilities, have been increasing considerably. It was concluded that research on agribusiness is expanding, in different areas of knowledge, allowing us to understand that this concept, supported by the network image, is less and less conditioned to agriculture in isolation, but to its productive chain. The article has yet a figure that resumes the future research studies.
\end{abstract}

Palavras-chave: Agribusiness; Web of Science; Bibliometria; Perspectivas agropecuárias; Agenda de pesquisas futuras. Keywords: Agribusiness; Web of Science; Literature review; Perspectives; Future research agenda. 


\section{INTRODUÇÃO}

A realidade do agronegócio está associada a uma série de mercados, com elevada diversidade de organizações (indústrias, propriedades agropecuárias, empresas de terceirização, dentre outros). Isso tem despertado o interesse da academia, implicando em uma gama de atividades científicas que, por sua vez, podem gerar diversos tipos de publicações científicas em várias áreas do conhecimento. O termo "agronegócio" começou a ganhar terreno no pós-guerra, com a nova percepção do entrelaçamento das relações travadas entre a produção dentro das propriedades rurais e o mundo mercadológico externo, além da formação de novos agentes (Cook; Chaddad, 2000).

A publicação do trabalho seminal de Davis e Goldberg, A concept of agribusiness, em 1957, cunha definitivamente o termo, ao sugerir a soma de todas as operações que envolvessem manufatura, processamento, estocagem e distribuição dos suprimentos oriundos das propriedades, criando assim, as "análises dos sistemas do agribusiness". Isso gerou um novo alicerce para se pensar as atividades baseadas na agricultura de sistemas, que antes isolava a agricultura produtiva dos demais setores (Heredia; Palmeira; Leite, 2010; Zylbersztajn, 2017).

A publicação de Davis e Goldberg circulou por legisladores, líderes empresariais e acadêmicos, disseminando a ideia de "agribusiness", que trouxe a possibilidade de se reformular as estratégias de trabalho nos mercados de fibra e alimentos, associadas a grandes corporações. Os autores foram além de discursos mais brandos sobre a fraqueza histórica do segmento agrícola, que demandaria aporte governamental, começaram a destacar a ascensão dos complexos verticais agrícolas. Assim, procuraram compreender onde (dentro da cadeia vertical) e quem conseguiria definir produção, insumos, preços, distribuição e, de forma adicional, quem ficava com a maior fatia financeira do processo. Logo, tal análise passou a constatar a relevância de grandes companhias, como a dos processadores de alimentos, ao passo que os produtores em si começaram a perder ganhos nesse processo (Hamilton, 2016).

O agronegócio passou a impactar o poder das nações, os hábitos de consumo, paisagens e a dinâmica do meio ambiente. Em linha, os esforços acadêmicos para investigar uma área tão densa também se expandiram, requerendo-se estudos cada vez mais abrangentes que abordassem, por exemplo, o mercado de commodities, das práticas conduzidas em propriedades rurais, os novos modelos de exploração e suas consequências, entre outros.
Tamanha pluralidade disciplinar redesenhou o modelo de agir e pensar o campo (Sutter, 2013).

Alguns autores buscaram compreender a multiplicidade de decorrências do agronegócio na sociedade por meio de pesquisas bibliométricas. Da Silva, De Oliveira e Garcia (2019) rastrearam o desenvolvimento de estudos sobre modelos para o agronegócio, almejando identificar a compreensão deste campo de pesquisa e quem seriam os principais atores envolvidos. Esses autores identificaram um crescimento significativo na produção acadêmica em torno da pauta, a partir de 2007, de sorte que Brasil e Estados Unidos (EUA) foram os países com maior volume de publicações sobre o tema. Nota-se ainda que o Brasil se destaca quanto à quantidade de periódicos, relevância das agências financiadoras e na frente de pesquisa. Segundo esses autores, essa constatação é pertinente, dado o destaque que o país tem no cenário internacional, bem como a importância que o agronegócio tem para a economia brasileira.

Lizot et al. (2016), por sua vez, propuseram um estudo bibliométrico para avaliar a produção acadêmica no que tange a Gestão de Custos no Agronegócio, a fim de fornecer um espectro confiável para pesquisadores que desejem se debruçar sobre o tema. Através da análise das principais bases indexadoras, acreditam ter conseguido formar um arcabouço de produções com o propósito de auxiliar futuras pesquisas nesta área de conhecimento, uma vez que, segundo esses autores, a amplitude de material disponível sobre o tema pode dificultar o acesso aos conteúdos mais importantes e aos autores mais relevantes.

Outro estudo que tem temática semelhante, realizou uma bibliometria das publicações no Congresso da Sociedade Brasileira de Economia, Administração e Sociologia Rural (SOBER), um dos principais congressos de economia rural do Brasil, de 2006 a 2009, que versavam sobre a viabilidade econômico-financeira em projetos de agronegócio. Destaca-se alguns dos seus resultados, como: o crescimento da utilização dessa ferramenta no agronegócio; identificaram a criação de pesquisas em grupos intra e interinstitucionais; e que o número de autores com uma citação, bem como baixa bibliografia, exibem que a produção muitas vezes não está sendo realizada por pesquisadores familiarizados com o tema (Macedo; Lunga, 2010).

Como visto, assuntos de grande relevância para nações e para a comunidade internacional, ainda mais quando articuladas a insumos de inúmeras indústrias, causam grande interesse à academia. Ademais, há uma profusão 
de possibilidades de conteúdo, ângulos e direções que podem instigar pesquisas científicas, com potencialidade de mutações céleres, facilitadas por inovações científicas, tecnológicas, legais, entre outros, que invertem seu modus operandi e, assim, os estudos científicos que os tangem. Essa é a situação do agronegócio.

Frente à importância desse tema, vários questionamentos surgem acerca do que tem sido discutido na literatura científica e que ainda não foram debatidos, permitindo indagações a respeito do comportamento das publicações e suas alterações ao longo das décadas, sobre quais seriam os autores mais citados, os periódicos mais relevantes e em quais países o tema é mais debatido. Destarte, o presente estudo teve por objetivo investigar o comportamento da literatura científica internacional sobre o agronegócio, a fim de poder pautar os temas que estão emergindo dentro do segmento. Para a sua consecução, este trabalho também se sustentou no método bibliométrico.

Isso se dá em razão dos estudos bibliométricos gerarem grande contribuição ao ambiente acadêmico, uma vez que sempre podem sugerir materiais diversos de pesquisa, com dados muitas vezes inesperados, ou que requerem comprovação. Por outro lado, como pôde ser observado, a literatura científica tem dado atenção apenas a subtópicos pontuais do tema agronegócio, não se dedicando, no entanto, aos temas que têm emergido, ao comportamento das publicações no decorrer do tempo, aos autores que têm se destacado numa esfera mais ampla, dentre outros aspectos. Portanto, este estudo tem uma característica que o difere dos demais, dado que busca estudar o tema em quase toda sua amplitude, sem fazer distinção de subtemas específicos. Como implicação, este trabalho contribui teoricamente à literatura científica, ao endereçar temas fortuitos de pesquisas futuras.

\section{METODOLOGIA}

Esta investigação é uma análise bibliométrica de artigos científicos, por se tratar de uma técnica estatística exploratória de natureza quantitativa, voltada para mensuração dos índices de produção e disseminação, que analisa o comportamento da literatura. Pesquisas exploratórias são especialmente importantes para maior familiarização, explicitar problemas ou aprimorar ideias sobre um determinado tema (Gil, 2002). Ademais, o método é consonante com o objetivo aqui proposto, visto que é capaz de indicar quais são os temas que estão emergindo na área de agronegócio, além de mudanças bruscas no processo acadêmico, quando ocorrem (Chen, 2006). Os dados possuem temporalidade longitudinal, visto que foram coletados entre os anos de 1956 a 2020.

Selecionou-se a base indexadora Web of Science (WoS), em virtude de ser considerada uma das principais bases do mundo; que abrange um amplo número de periódicos bem qualificados mundialmente; que compila material de diversos campos do saber; e, que possui políticas sérias de inclusão e exclusão de periódicos (Wang; Waltman, 2016; Martins; Lucato, 2018; Duque; Cervantes, 2019).

A pesquisa foi realizada no dia 13 de abril de 2020, utilizando a seguinte string de busca: $T I=$ (agrobusiness $O R$ agribusiness). Aplicou-se filtros que pudessem selecionar apenas artigos e reviews, mas sem nenhuma limitação de ano, área ou periódico. Em função de se ter buscado artigos que apresentem os termos de interesse no título, não foram excluídos trabalhos por procedimentos posteriores a busca, a fim de que fossem identificados os diferentes enfoques dados ao agronegócio ao longo do tempo. Isso porque assume-se que trabalhos que citam o termo no título abordam efetivamente o tema de interesse. Após a aplicação da string de busca na ferramenta de pesquisa avançada da referida base de dados, os resultados revelaram um total de 787 trabalhos publicados.

Após a definição da amostra, realizou-se a exportação dos dados para o software EndNote ${ }^{\circledR}$, que permitiu que a organização e armazenamentos ocorressem de forma apropriada. Tal procedimento é especialmente importante para que, caso houvesse necessidade de eventuais consultas ao banco de dados posteriormente, somente seriam possíveis se os mesmos estivessem devidamente organizados e armazenados. Foi verificada a existência de inconsistências no banco de dados, tais como duplicidade de artigos e publicações que, eventualmente, pudessem não estar completas, não sendo identificado nenhuma publicação que precisasse ser excluída (Chen, 2006).

Em uma planilha do Excel $^{\circledR}$, foi elaborada a matriz de análise, necessária para a interpretação dos dados. Utilizou-se também o software CiteSpace ${ }^{\circledR}$ para realizar as análises bibliométricas. Este software, em linguagem de programação Java, permite visualizar e analisar redes de citação e cocitação, com o intuito de detectar o surgimento de termos emergentes, em um campo específico (Chen, 2006). Para a análise dos dados, seguiu-se os preceitos apresentados por Chen (2006) que indicaram a existência de duas análises.

A primeira, denominada análise da frente de pesquisa (research front) compreende os artigos do conjunto. Mostram os agrupamentos transitórios dos trabalhos acerca do tema e o movimento que promovem no campo 
científico, à medida que novos artigos substituem e/ou complementam os artigos existentes. No segundo, denominando base intelectual (intellectual base), os resultados envolvem a análise das referências citadas pelos artigos aqui estudados, evidenciando vestígios das citações e cocitações na literatura científica, que evoluem como uma rede de publicações citadas pelos autores da frente de pesquisa (Chen, 2006).

A análise da frente de pesquisa foi realizada de forma categorizada. Primeiramente, analisou-se as citações dos artigos selecionados. Posteriormente, verificou-se os países de origem dessas publicações, bem como quais foram os periódicos que mais publicaram. Analisou-se as relações de autoria e coautoria entre as obras, as palavraschave utilizadas nos artigos e a área das publicações. Para tanto, considerou-se as categorias de áreas apresentadas na base de dados WoS. Por fim, realizou-se a análise da base intelectual, investigando as redes de cocitações dos autores e periódicos mais citados.

Todos esses procedimentos supracitados contribuíram para que fosse possível identificar as principais áreas de pesquisa, autores, periódicos e países que mais publicaram sobre o tema agronegócio, bem como a interação entre eles. O Quadro 1 apresenta um detalhamento do percurso metodológico utilizado nesta pesquisa para melhor elucidar os procedimentos metodológicos adotados.

QUADRO 1 - Procedimentos metodológicos da bibliometria

\begin{tabular}{|c|c|c|c|}
\hline Etapa & Procedimento & & Descrição \\
\hline \multirow{2}{*}{1} & \multirow{2}{*}{ Operacionalização da pesquisa } & 1.1 & Escolha da base científica: Web of Science (WoS) \\
\hline & & 1.2. & Delimitação dos termos que representam o campo \\
\hline \multirow{5}{*}{2} & \multirow{5}{*}{ Procedimentos de busca (filtros) } & 2.1. & Title (termo do campo) \\
\hline & & 2.2 & Filtro 1: Delimitação em somente artigos e reviews \\
\hline & & 2.3 & Filtro 2: Todos os anos \\
\hline & & 2.4 . & Filtro 3: Todas as áreas \\
\hline & & 2.5 . & Filtro 4: Todos os idiomas \\
\hline \multirow{6}{*}{3} & \multirow{6}{*}{$\begin{array}{l}\text { Procedimentos de seleção (Banco de } \\
\text { dados) }\end{array}$} & 3.1. & Download das referências - software EndNote \\
\hline & & 3.2 . & Download das referências - planilha eletrônica $\left(\right.$ Excel $\left.^{\circledR}\right)$ \\
\hline & & 3.3. & Download das referências - CiteSpace \\
\hline & & 3.4 . & Organização das referências - EndNote \\
\hline & & 3.5 . & Organização de matriz de análise em planilha eletrônica \\
\hline & & 3.6. & Importação dos dados para softwares de análise \\
\hline 4 & Adequação e organização dos dados & 4.1. & Busca dos artigos completos em .pdf \\
\hline \multirow{7}{*}{5} & \multirow{7}{*}{$\begin{array}{l}\text { Análise da Frente de Pesquisa } \\
\text { (Research front) }\end{array}$} & 5.1 & Análise do volume das publicações e tendências temporais \\
\hline & & 5.2. & Análise de citações dos artigos selecionados \\
\hline & & 5.3 & Análise dos países dos artigos selecionados \\
\hline & & 5.4 . & Análise dos periódicos que mais publicaram \\
\hline & & 5.5 & Análise da autoria e coautoria \\
\hline & & 5.6. & Análise das categorias (áreas) das publicações \\
\hline & & 5.7. & Análise das palavras-chave \\
\hline \multirow{2}{*}{6} & \multirow{2}{*}{$\begin{array}{l}\text { Análise da Base Intelectual } \\
\quad \text { (Intellectual base) }\end{array}$} & 6.2 & Análise da rede de cocitações dos autores mais citados \\
\hline & & 6.3. & Análise da rede de cocitações dos periódicos mais citados \\
\hline \multirow{3}{*}{7} & \multirow{3}{*}{ Framework para agenda de pesquisa } & 7.1. & Leitura dos principais artigos do Research front \\
\hline & & 7.2 . & Leitura dos artigos (2018 a 2020) da Intellectual base \\
\hline & & 7.3 . & Endereçamento de estudos futuros \\
\hline
\end{tabular}

Fonte: Adaptado de Prado et al. (2016)

Organizações Rurais \& Agroindustriais, Lavras, v. 23, e1737, 2021 
O último procedimento realizado consistiu na leitura dos principais artigos da frente de pesquisa (independente do ano de publicação) e da base intelectual, referente apenas aos últimos anos da amostra (2018 a 2020). Essas leituras foram fundamentais para identificar as principais lacunas existentes na literatura e, com isso, propor um framework para agenda de pesquisas.

\section{RESULTADOS E DISCUSSÃO}

Uma vez que a análise dos dados considerou a frente de pesquisa e a base intelectual, apresentar-se-ão os resultados respeitando essa subdivisão.

\subsection{Frente de pesquisa}

Desde a primeira publicação (1956), pôde-se observar a ocorrência de um salto temporal entre as publicações, já que a segunda publicação ocorreu nove anos depois, em 1964, e, desde então, houve publicações em todos os anos, até 2020 (Figura 1). Outro aspecto a ser destacado é o aumento significativo nas publicações de 1967 a 1969. Em 1967, houve uma publicação; em 1968, oito; e, em 1969, dezesseis publicações sobre o tema. A partir de 2008, as publicações cresceram anualmente até 2019, ano com maior número de publicações, com um total de 93 trabalhos. As publicações de 2020 não foram consideradas em sua totalidade, visto que a pesquisa ocorreu em meados de abriu do referido ano.
Constata-se que há, atualmente, interesse acadêmico acerca das operações envolvidas na produção, distribuição e comercialização de produtos agrícolas e, em especial, ao se considerar essa cadeia produtiva como o pano de fundo para o desenvolvimento do agribusiness. Nesse sentido, verificou-se uma taxa média de crescimento anual de 38,3\% nas publicações de trabalhos científicos. A taxa de crescimento nessas publicações foi maior que aquela apontada por Bornmann e Mutz (2015) sobre ciência que, também utilizando a base de dados Web of Science, demonstraram que o número de publicações científicas, cresceu entre $8 \%$ e $9 \%$ após a Segunda Guerra Mundial, até o ano de 2012.

O termo agribusiness foi mencionado pela primeira vez no artigo publicado por Davis (1956). Segundo esse autor, o agronegócio é considerado a soma de todas as operações provenientes da agricultura, ou seja, desde a produção, fabricação e distribuição de produtos agrícolas. Essa definição foi considerada como ponto de partida para as discussões sobre o tema, e também como evolução do conceito. Davis, agora junto a Goldberg, acrescentaram na definição os processos de produção em propriedades rurais como armazenamento, processamento e distribuição de produtos agrícolas, e os itens provenientes destes produtos (Davis; Goldberg, 1957). Apesar da terminologia agribusiness ser a mais utilizada, identifica-se também trabalhos que fazem uso do termo agrobusiness. Sobre isso, o primeiro trabalho a citar esse termo foi Gorenstein (1998).

Taxa média de crescimento anual: $38,3 \%$

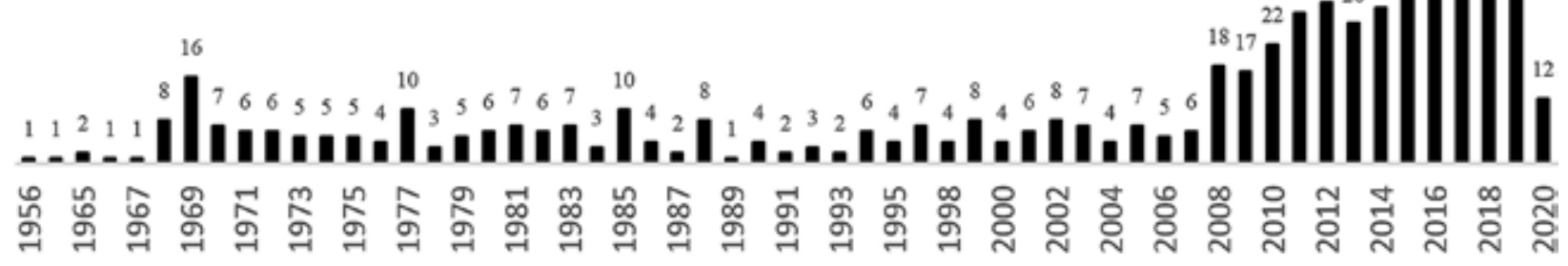

FIGURA 1 - Temporalidade das publicações de 787 artigos indexados na base de dados Web of Science, com foco em agronegócio, de 1956 a 2020

Fonte: Elaborado pelos autores (2020) 
A Tabela 1 mostra os cinco trabalhos mais citados da amostra. $\mathrm{O}$ artigo Willingness-to-pay estimates and their relevance to agribusiness decision making, de Lusk e Hudson (2004), foi o mais influente, com 112 citações, atingindo uma média de 6,59 citações por ano desde sua publicação, em 2004. Porém, esse artigo apresentou média anual de citações inferior a outros artigos como os trabalhos de Candido et al. (2014) e Cáceres (2014), cujas médias anuais foram de 7,86 e 11,33 citações, respectivamente. Embora tenham sido menos citados no decorrer dos anos, esses trabalhos tiveram maior ênfase no que tange às citações recebidas anualmente. Também é válido mencionar que são trabalhos mais recentes e por isso estão disponíveis à academia a menos tempo.

Observou-se uma pluralidade nas naturezas constitutivas dos artigos mais mencionados, indicando certa amplitude das possibilidades quanto às abordagens e discussões a respeito do tema. Lusk e Hudson (2004) mostraram as relações decorrentes ao interesse dos consumidores em pagarem por novos produtos disponibilizados no mercado e como essa demanda pode orientar as tomadas de decisão dos atores envolvidos no agronegócio.

Zhang e Donaldson (2008) demonstraram o processo de evolução das atividades rurais na China, em consonância ao capitalismo, em que as transformações ocorridas geraram impactos significativos nas políticas públicas, sociais e econômicas em relação ao setor do agronegócio chinês. Já Cáceres (2014) analisou as consequências das transformações no agronegócio na Argentina que, a partir das políticas públicas de 2001, ocorreram diversas mudanças sociais e econômicas no setor, promovendo a expansão do capital agrário e da concentração de riqueza entre os players envolvidos no setor argentino.

Candido et al. (2014), por sua vez, conseguiram retratar a relevância das relações moleculares derivadas de plantas e o uso adequado em aplicações para a saúde humana, com efeito nas operações do agronegócio, tais como alimentos transgênicos. Amanor (2012) explorou as maneiras pelas quais as políticas agrícolas contemporâneas e as reformas neoliberais do mercado refletiram nas políticas do agronegócio da África. Tais transformações, segundo o autor, repercutiram na desigualdade de competitividade entre os pequenos e grandes produtores agrícolas, o que gerou discrepâncias entre as atividades integradas às cadeias de marketing do agronegócio.

Os estudos de Zhang e Donaldson (2008), Amanor (2012) e Cáceres (2014) focaram nas relações de transformação das políticas públicas, sociais e econômicas do setor agrícola, em diferentes regiões do mundo. Entretanto, os objetivos de discussão permeiam as relações intrínsecas à cadeia agroindustrial e a sua evolução durante o tempo, atravessando as consequências entre os agentes da cadeia, afetando a demanda e oferta dos produtos do agronegócio local e mundial.

Os trabalhos de Lusk e Hudson (2004) e Amanor (2012) revelam a atualidade dos conceitos abarcados nas décadas de 1950 e 1960 . O primeiro aborda a teoria do processo decisório (algo muito mais próximo ao conceito que marcou o pensamento inicial do agronegócio). Já o segundo, volta a retratar as trajetórias institucionais da cadeia do agronegócio, reportando elementos importantes ao início das pautas levantadas pelos primeiros artigos sobre o tema, como as pressões nos preços de commodities e as relações intergovernamentais como, por exemplo, os países africanos.

TABELA 1 - Estudos e autores mais citados em 787 artigos indexados base de dados Web of Science, com foco em agronegócio, de 1956 a 2020

\begin{tabular}{ccccc}
\hline Título & Autor (Ano) & Periódico & Total de citações & Média (citações/ano) \\
\hline $\begin{array}{c}\text { Willingness-to-pay estimates and their } \\
\text { relevance to agribusiness decision making }\end{array}$ & $\begin{array}{c}\text { Lusk e Hudson } \\
(2004)\end{array}$ & $\begin{array}{c}\text { Review of Agricultural } \\
\text { Economics }\end{array}$ & 112 & 6,59 \\
$\begin{array}{c}\text { The rise of agrarian capitalism with Chinese } \\
\text { characteristics: agricultural modernization, } \\
\text { agribusiness and collective land rights }\end{array}$ & $\begin{array}{c}\text { Zhang e } \\
\text { Donaldson } \\
(2008)\end{array}$ & China Journal & 78 & 6,00 \\
$\begin{array}{c}\text { Accumulation by Dispossession and Socio- } \\
\text { Environmental Conflicts Caused by the }\end{array}$ & $\begin{array}{c}\text { Cáceres } \\
\text { Expansion of Agribusiness in Argentina }\end{array}$ & $\begin{array}{c}\text { Journal of Agrarian } \\
\text { Change }\end{array}$ & 68 & 11,33 \\
$\begin{array}{c}\text { The use of versatile plant antimicrobial } \\
\text { peptides in agribusiness and human health } \\
\text { Global resource grabs, agribusiness }\end{array}$ & $\begin{array}{c}\text { Candido et al. } \\
(2014)\end{array}$ & Peptides & 55 & 7,86 \\
$\begin{array}{c}\text { concentration and the smallholder: two West } \\
\text { African case studies }\end{array}$ & $\begin{array}{c}\text { Amanor } \\
(2012)\end{array}$ & $\begin{array}{c}\text { Journal of Peasant } \\
\text { Studies }\end{array}$ & 48 & 5,33 \\
\hline
\end{tabular}

Fonte: Elaborado pelos autores (2020)

Organizações Rurais \& Agroindustriais, Lavras, v. 23, e1737, 2021 
A Figura 2 complementa os resultados apresentados pela Tabela 1, supracitada. Além de destacar os trabalhos mais citados, por intermédio da variação no tamanho das letras (quanto maior à letra, e maior quantidade de citações), ela mostra a rede de citações feitas pelos artigos estudados, indicando que artigos interligados na rede foram citados paralelamente em outros trabalhos. Pode-se constatar que as redes mais fortes (cujas linhas aparecem em maior destaque) não foram compostas pelos trabalhos mais citados, indicativo que, apesar de bem-conceituados pelos autores do tema, eles não foram utilizados de maneira complementar.

Em relação aos países em que as pesquisas foram realizadas, o Brasil se destaca, com 193 publicações (Figura 3). O significativo impacto do agronegócio no Produto Interno Bruto (PIB) nacional (Barros et al., 2020) pode ser um fator que ajuda a explicar esse comportamento. Concomitantemente, o Brasil tem realizado investimentos em pesquisa e desenvolvimento da produtividade agrícola, sendo muito exitosos no aumento da produção, sem que haja igual proporção na expansão territorial da produção (Pereira; De Castro, 2017).

Em seguida, aponta-se os Estados Unidos da América (EUA), com 147 artigos publicados. Nota-se que, nesse país, o agronegócio se caracteriza por números bastante significativos. Em 2018, o setor representou 11\% dos empregos gerados e, entre 2007 e 2017, o setor de produção agrícola representou 5,4\% do PIB norte-americano (USDA, 2018; 2020). Observa-se uma relação interessante, cujo tema agronegócio tem se destacado cientificamente com as publicações provenientes de países (majoritariamente, Brasil e Estados Unidos da América) com grande produção de alimentos e com expressão mundial nas operações pertinentes ao setor agrícola (EMBRAPA, 2018; USDA, 2020).

É válido analisar também o nível de intermediação que as publicações dos países exerceram com os demais, presentes na rede (Figura 3). A quantidade de caminhos de cada país intermedia as conexões entre os nós referentes às nações, isto é, pelo grau em que o nó faz parte dos caminhos que conectam um par arbitrário de nós na rede (Chen, 2006). Constata-se que os EUA é o país com maior nível de centralidade (12), seguido pela Inglaterra (8) e Brasil (7). Dessa forma, pode-se afirmar que, ao considerar o conjunto de artigos estudados, pesquisadores das nações supracitadas promovem uma maior interligação entre estudiosos de diferentes nacionalidades.

Entretanto, apesar de o Brasil se caracterizar pelo maior montante de trabalhos publicados, não é o país com maior quantidade de pesquisas em parceria com estudiosos de outros países. Isso é importante ao considerar o intercâmbio de conhecimento entre pesquisadores de diferentes países, que realizam suas pesquisas em contextos distintos e que, juntos, podem colaborar para o desenvolvimento do tema. Tal condição pode indicar uma lacuna nas pesquisas brasileiras sobre agronegócio, visto que parece não haver muita internacionalização do conhecimento científico quando comparado a outros países.

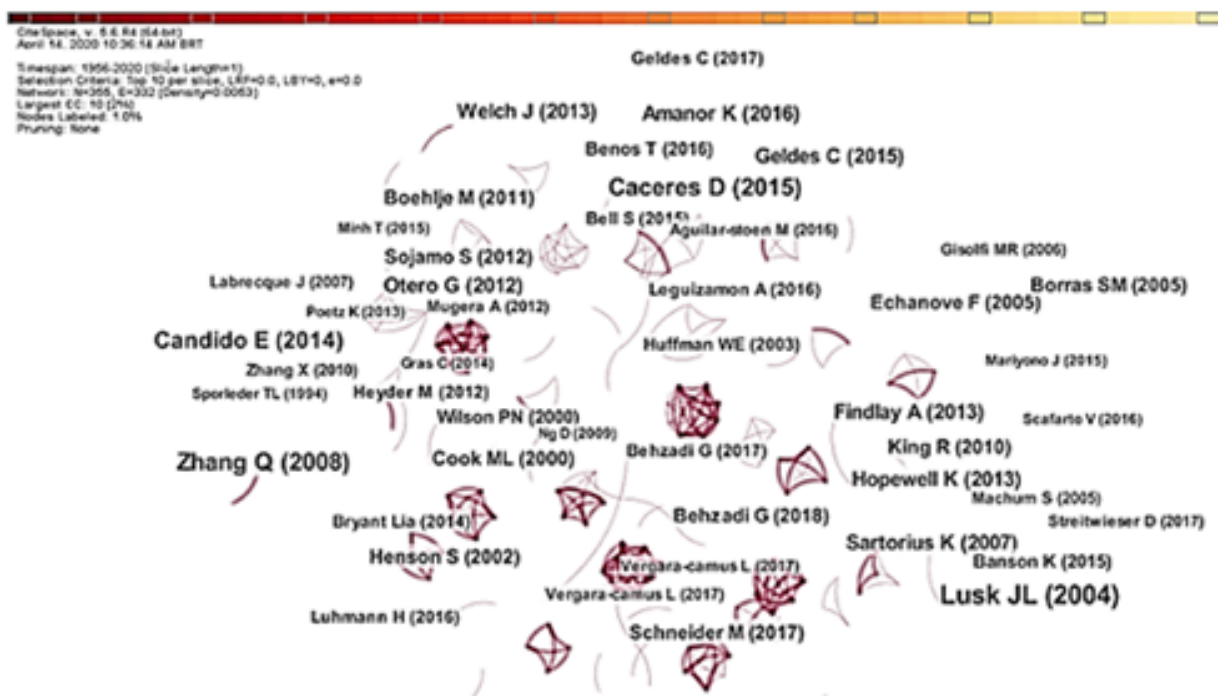

FIGURA 2 - Rede de citação dos artigos mais citados em publicações de 787 artigos indexados na base de dados Web of Science, com foco em agronegócio, de 1956 a 2020

Fonte: Elaborado pelos autores (2020) 


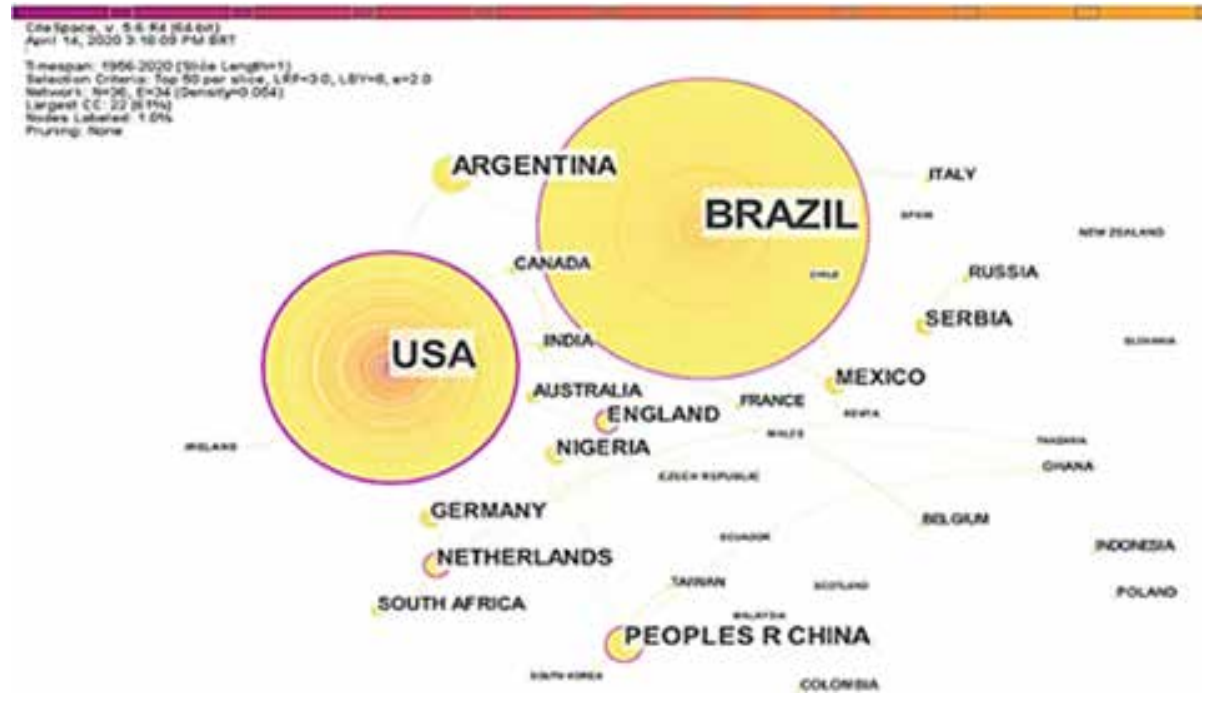

FIGURA 3 - Países que mais publicaram artigos científicos indexados na base de dados Web of Science, com foco em agronegócio, de 19656 a 2020

Fonte: Elaborado pelos autores (2020)

Outra análise importante para estudos de bibliometria são as publicações por periódicos e seus países de origem. Neste sentido, a Tabela 2 destaca os principais periódicos responsáveis pela publicação de 245 trabalhos, representando $31,2 \%$ do total das publicações da amostra.

O Brasil ocupa a segunda colocação, com três dos 11 periódicos que mais publicaram sobre o tema $\left(\mathrm{N}^{\mathrm{o}} 1\right.$, 8 e 10; Tabela 2), totalizando 71 artigos. Perdem apenas para os Estados Unidos, que possuem seis periódicos $\left(\mathrm{N}^{\mathrm{o}}\right.$ 2, 3, 4, 5, 6, e 11; Tabela 2), com 151 artigos ao todo. Esses resultados reforçam a importância das pesquisas brasileiras em todo o mundo sobre o agronegócio, visto que $9,0 \%$ de todas as publicações são nacionais. O periódico Custos e Agronegócio On-line (brasileiro) detém 49 publicações, representando $6,2 \%$ do total das publicações sobre o tema. O segundo periódico com mais publicações é o International Food and Agribusiness Management Review (norte-americano), com 47 publicações. Os EUA possuem grande relevância nas publicações científicas ao redor do mundo, com forte concentração de veículos de publicação científica em diversas áreas do conhecimento.

Observou-se que, no geral, grande parte dos artigos publicados pelos principais periódicos (Tabela 2) analisou processos intrínsecos à produção de alimentos provenientes da agricultura, como: cadeia de suprimentos, dados econômicos e de custos da produção, além de aspectos relativos à evolução das operações agrícolas que geram impactos sociais, ambientais, econômicos e nas políticas públicas de governos de diferentes países, tais como China, Argentina e Brasil. É notório o impacto da concepção teórica de agronegócio, coligando todos os estágios pré e pós-produção, e não apenas o setor agrícola em si.

A Figura 4 mostra a rede de autoria e coautoria formada a partir dos artigos presentes na amostra. Além de evidenciar os pesquisadores que publicaram trabalhos juntos, revela, a partir do tamanho dos nós, aqueles com maior quantidade de trabalhos publicados sobre o tema.

G. F. Carini. e R. Berglund foram os pesquisadores com maior quantidade de publicações no conjunto, sendo ambos autores em cinco trabalhos cada. Carini foi o primeiro autor em quatro desses cinco artigos, sendo segundo autor em apenas um deles, enquanto Berglund foi o primeiro autor nos cinco trabalhos que participou. Em seguida destaca-se F. D. Kakhki, S. A. Freeman, G. A. Mosher, A. J. Connolly e K. Wu, com três publicações cada. É importante ressaltar que os três primeiros trabalharam juntos nos três artigos publicados por eles, sendo, inclusive, observado nas conexões entre os autores.

Adicionalmente, a escala de cor representa a evolução temporal dos artigos, isto é, os autores com conexões próximas ao roxo, possuem publicações mais antigas, enquanto que as conexões próximas ao amarelo, remetem a publicações mais recentes. Assim, percebe-se que dentre os autores com maior montante de publicações, com exceção de Berglund, todos tiveram seus trabalhos publicados recentemente. 
TABELA 2 - Periódicos indexados à base de dados Web of Science que mais publicaram sobre o tema agronegócio, de 1956 a 2020

\begin{tabular}{|c|c|c|c|c|}
\hline & \multirow{2}{*}{ Periódico } & \multirow{2}{*}{$\begin{array}{c}\text { Freq. }\left(\mathrm{N}^{\mathrm{o}}\right) \\
\text { Total }^{*}\end{array}$} & \multicolumn{2}{|c|}{ Frequência relativa $(\%)$} \\
\hline & & & Cumulativa & \\
\hline 1. & Custos e Agronegócio on-line & 49 & 6,2 & 6,2 \\
\hline 2. & International Food and Agribusiness Management Review & 47 & 6,0 & 12,2 \\
\hline 3. & American Journal of Agricultural Economics & 38 & 4,8 & 17,0 \\
\hline 4. & Feedstuffs & 25 & 3,2 & 20,2 \\
\hline 5. & Agricultural Education & 17 & 2,2 & 22,4 \\
\hline 6. & Agribusiness & 14 & 1,8 & 24,1 \\
\hline 7. & Ekonomika Poljoprivreda-Economics of Agriculture & 13 & 1,7 & 25,8 \\
\hline 8. & Custos e Agronegócio & 12 & 1,5 & 27,3 \\
\hline 9. & Agricultural Economics-Zemedelska Ekonomika & 10 & 1,3 & 28,6 \\
\hline 10. & Revista Pegada & 10 & 1,3 & 29,9 \\
\hline 11. & Sustainability & 10 & 1,3 & 31,2 \\
\hline & Total & 245 & 31,2 & - \\
\hline
\end{tabular}

* Considera-se a representatividade da quantidade de publicações sobre o total da amostra (787 artigos).

Fonte: Elaborado pelos autores (2020)

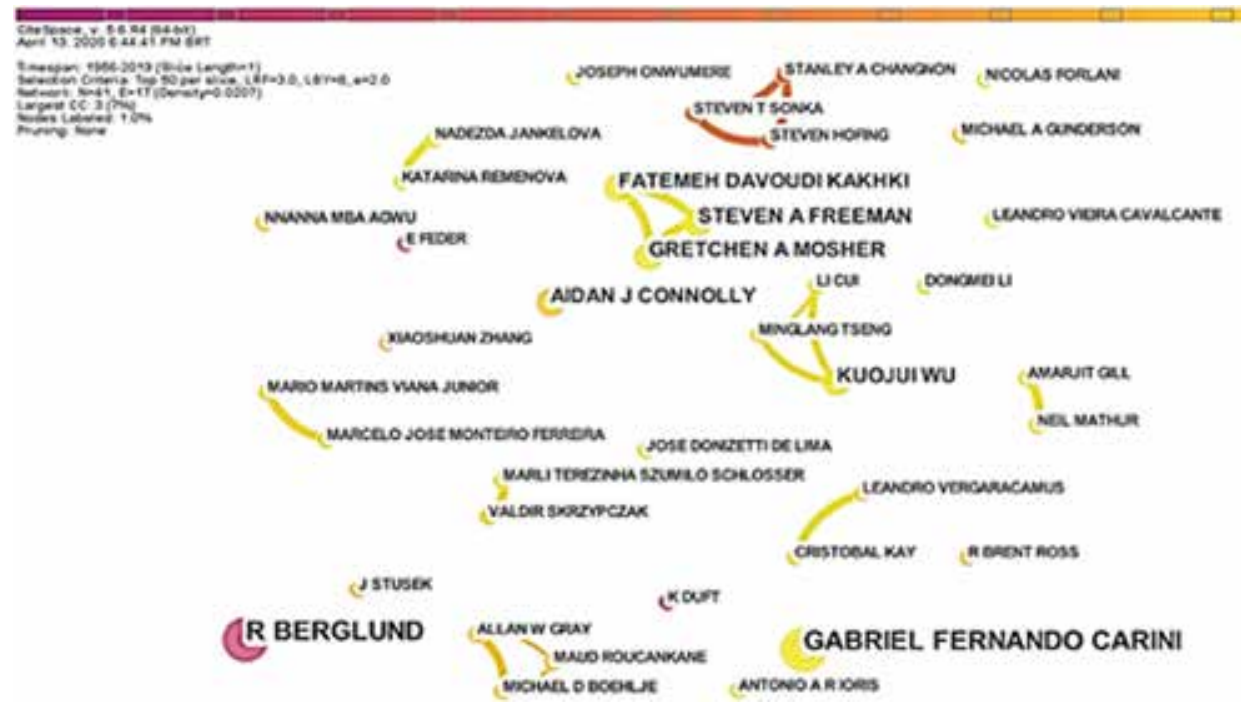

FIGURA 4 - Rede de autoria e coautoria de 787 artigos indexados na base de dados Web of Science, com foco em agronegócio, de 1956 a 2020

Fonte: Elaborado pelos autores (2020)

A Figura 5 mostra a evolução das categorias em que os artigos foram indexados. Assim, é possível identificar como o tema foi abordado ao longo do tempo e quais categorias surgiram nos últimos anos. Ao considerar a escala de cores, partindo de cores próximas ao roxo para o amarelo, percebe-se que mesmo as primeiras categorias a surgirem, como
Agronomy e Agriculture, Dairy \& Animal Science, são compostas majoritariamente por estudos recentes, o que reafirma o atual enfoque acadêmico ao agronegócio. Indica também o crescimento das publicações sobre do tema nos últimos anos. A historicidade dos estudos em agronegócio reflete sua evolução, incorporando elementos de outras disciplinas. 
O começo da produção científica aqui identificada revela a trajetória seguida pelo conceito (Figura 5). Nos anos iniciais, observou-se uma predominância de estudos voltados para a agronomia, agricultura, economia, política e negócios. Com o passar dos anos, os estudos no agronegócio foram recebendo aportes teóricos diversos. Temas como ciências sociais, geografia, ciências dos alimentos e tecnologia, entre outros, ganham força nas décadas de 1980 e 1990, emergindo pesquisas mais voltadas para outros campos, tais como meio ambiente e sustentabilidade. Essas novas áreas, por sua vez, foram ganhando, se ampliando, correlacionando a cadeia produtiva às suas consequências ambientais. Evidentemente, tais tópicos se entrelaçam com os demais; por exemplo, a correlação entre economia, política e meio-ambiente fica ainda mais densa e conectada, o que explica a dificuldade de protagonismo de apenas uma categoria.

Isso coaduna com as posições levantadas por Sutter (2013), ao afirmar que o estudo do meio ambiente ascendeu exponencialmente desde as décadas de 1960 e 1970, reforçando a ideia de que o ser humano avançava e destruía, compulsivamente. $\mathrm{O}$ autor alertou sobre a necessidade de estudos que indicassem a importância acerca da proteção do meio ambiente. Ainda segundo ele, os pesquisadores desenvolveram complexos termos e narrativas para descrever o percurso de uma humanidade destrutiva, para uma humanidade que entende seus processos e implicações sobre o meio ambiente. Terminologias como segunda natureza, máquinas orgânicas, sistemas ecotecnológicos etc., revelam o entrelaçamento entre o agronegócio e o meio ambiente (Sutter, 2013).
Conforme indicam os resultados desta pesquisa, no decorrer dos anos, tem-se aumentado significativamente a quantidade de pesquisas sobre o agronegócio em áreas que, outrora, eram pouco estudadas. Tal condição implica em uma maior diversificação do entendimento sobre como se dão as interfaces entre o agronegócio e as mais diversas áreas. Nesse sentido, no contexto atual, a maior diversidade de pesquisas permite que pesquisadores investiguem questões relacionadas ao tema sob diferentes lentes, contribuindo com uma maior evolução do conhecimento científico e suas implicações no agronegócio.

No que se refere à quantidade de publicações, apontase, em ordem decrescente, as categorias: Agriculture (346); Business \& Economics (258); Agricultural Economics \& Policy (244); Economics (176); Business (94); Agronomy (57); Environmental science \& Ecology (46); Management (46); Agriculture, Multidisciplinary (44) e Geography (38). Já sobre a centralidade, também se destaca a categoria Agriculture, cujo valor foi de 35. Ao considerar o nível de intermediação que tal categoria propiciou entre as demais, é possível dizer que apesar do surgimento de tantas outras, Agriculture ainda permanece como o ponto que interliga os demais enfoques dados ao agronegócio.

Dentre as publicações analisadas, verificou-se as principais palavras-chave utilizadas nos artigos (Figura 6). A quantidade total de palavras-chave da amostra foi de 1.908, sendo 1.025 distintas entre si. Sobressai-se o termo agribusiness, ao qual foi citado em 190 artigos. Em seguida, aponta-se os termos: performance, com 39 citações e agricultura, com 33 citações.

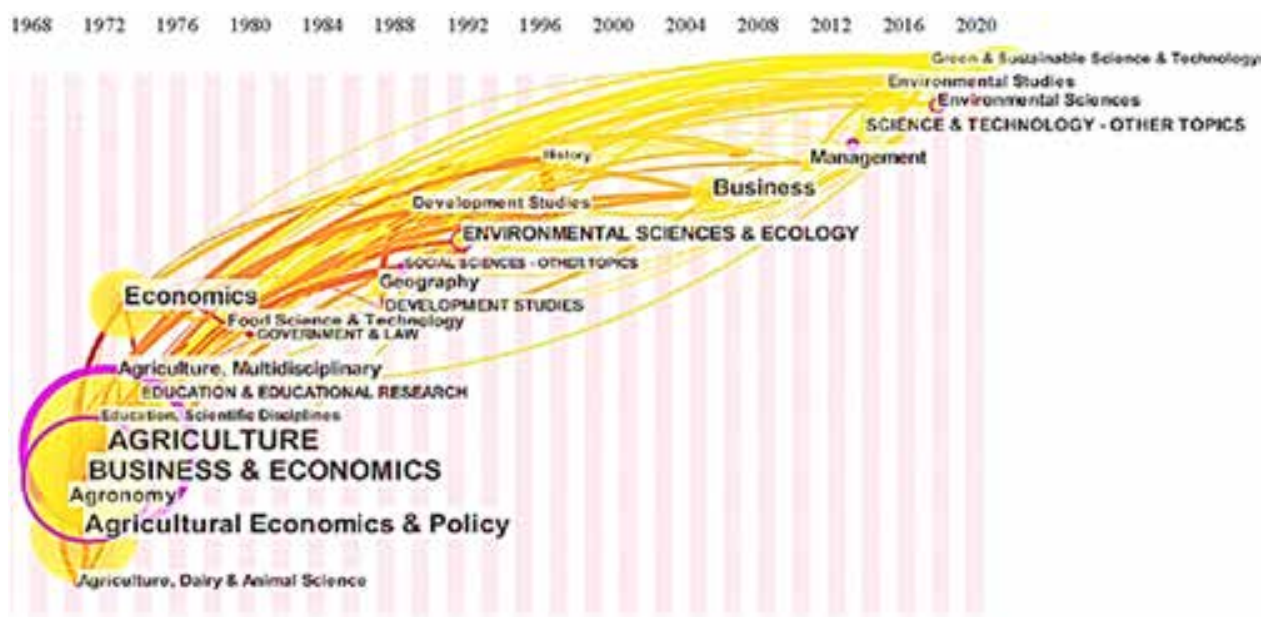

FIGURA 5 - Evolução das categorias de artigos indexados na base de dados Web of Science, com foco em agronegócio, de 1956 a 2020

Fonte: Elaborado pelos autores (2020)

Organizações Rurais \& Agroindustriais, Lavras, v. 23, e1737, 2021 


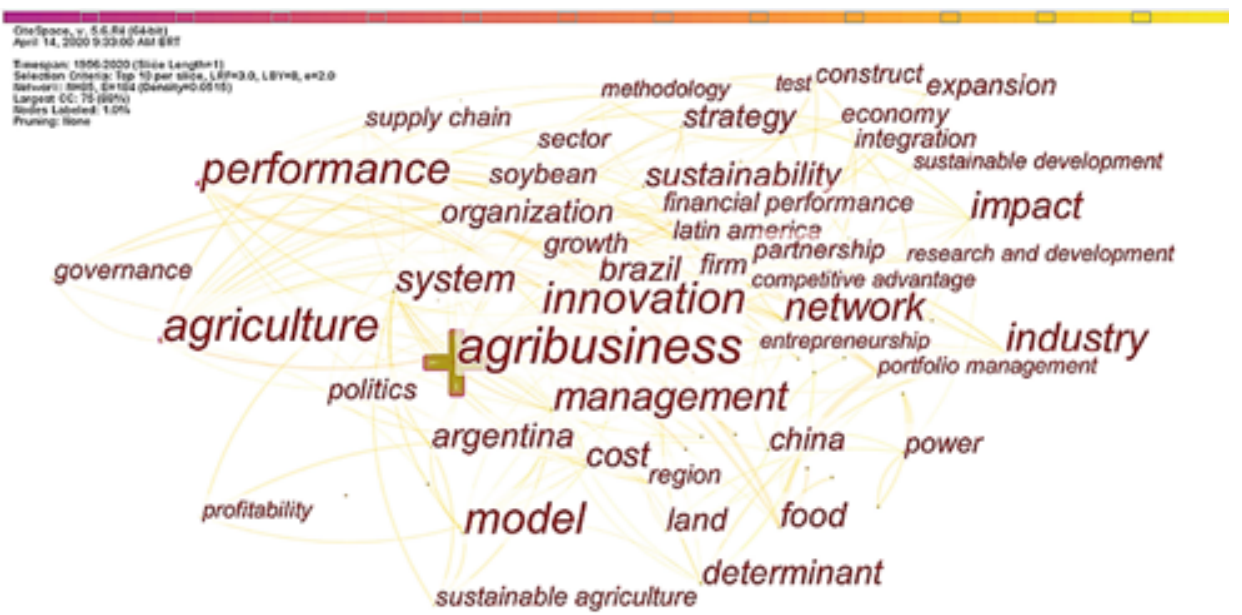

FIGURA 6 - Rede de palavras-chave identificadas em 787 artigos indexados pela base de dados Web of Science, com foco em agronegócio, de 1956 a 2020

Fonte: Elaborado pelos autores (2020)

Percebe-se que o uso das palavras-chave nas publicações estão, direta ou indiretamente, ligadas à ideia central de agribusiness, sendo confirmado pela sua maior centralidade (25) (Figura 6). Esse termo promoveu a maior interligação entre os demais, seguido por agriculture e innovation, cujas centralidades foram 18 e 15, respectivamente. As palavras-chave mostram alguns dos principais enfoques dos trabalhos e retratam detalhes de investigação executados nos artigos. Também são importantes por demonstrarem temas de interesses que os autores têm trabalho na literatura sobre o tema. Não se pode deixar de pontuar a grande diversidade de palavras-chave identificadas na literatura pesquisada. Esses resultados reforçam o entendimento de que os estudos sobre o agronegócio estão em expansão, indicativo de que seja um tema emergente e relevante para a comunidade científica.

\subsection{Base Intelectual}

A Figura 7 apresenta a rede de cocitação, composta pelos autores presentes nas referências dos artigos do conjunto. Sua importância advém do fato de que nem todos os trabalhos significativos para determinada área aparecem nas buscas realizadas nas bases, seja por não estarem indexados, serem publicados em tipos de documentos distintos como relatórios e livros, pela antiguidade, entre outros fatores que podem prejudicar a identificação de obras importantes. Destaca-se a significativa citação do World Bank e Michael Porter, ao qual não seriam identificados somente pela frente de pesquisa.
A Figura 7 reforça algumas das análises anteriores. Entre elas, o entrelaçamento com outras disciplinas, que pode explicar o porquê de Michael Porter, um autor clássico da Administração Estratégica, estar em destaque como o segundo em volume de citações. Nota-se também que, não um autor, mas uma organização, o World Bank, se destaca como o mais citado (33 citações). World Bank é a maior organização mundial para o desenvolvimento, com mais de 180 países associados. Tem um trabalho multidisciplinar, composto por cientistas políticos e sociais, economistas e especialistas de diversas áreas. Dedica-se à erradicação da pobreza extrema, prestação de suporte para o crescimento econômico, melhoria da qualidade de vida e ajuda aos países a se desenvolverem (World Bank, 2020).

No que se refere à base intelectual, caracterizado pela maior intermediação entre os demais, o autor mais citado foi Boehlje M., cuja centralidade foi 43. O trabalho que evidenciou sua maior centralidade foi publicado em 1999, chamado Structural Changes in the Agricultural Industries: How Do We Measure, Analyze and Understand Them?

Ao destacar as mudanças estruturais no que tange a produção e distribuição de alimentos, produção e consumo mundial, tecnologia, tamanho da operação e localização geográfica da época, Boehlje (1999), buscou identificar: (i) dimensões importantes dessas mudanças; (ii) questões críticas de gestão e políticas públicas que passaram a ser demandadas em função delas; (iii) motivações ou combinações destas por trás das decisões dos agentes econômicos que criaram ou colaboraram para 
ocorrência da maioria das mudanças; (iv) características e consequências dessas mudanças para o futuro da indústria; (v) estruturas conceituais tradicionais; e (vi) conjuntos de dados e técnicas de análise empírica $e x$ post que pudessem fornecer a capacidade analítica para entender essas profundas mudanças estruturais. Dessa forma, percebe-se que o autor, em um único trabalho, buscou suprir seis lacunas, o que pode ter colaborado para a promoção da intermediação de seu estudo.
A Figura 8 evidencia os periódicos cujos trabalhos publicados apareceram com maior frequência nas referências dos artigos da amostra ao longo do tempo e mostra em que áreas esses estudos foram empregados.

Dentre o material presente na base intelectual, vê-se igualmente um crescimento de publicações sobre o agronegócio em periódicos interdisciplinares. Em especial, destacam-se os veículos de publicação relacionados à ciência da computação e sistemas informacionais.

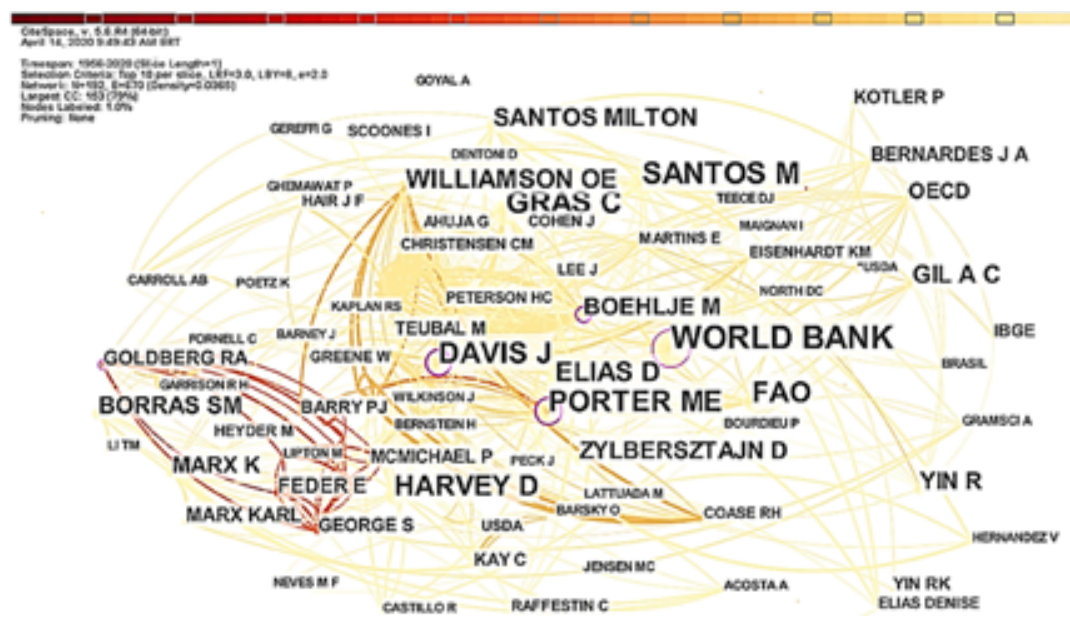

FIGURA 7 - Rede de cocitação (autores citados) de 787 artigos indexados na base de dados Web of Science, com foco no agronegócio, de 1956 a 2020

Fonte: Elaborado pelos autores (2020)

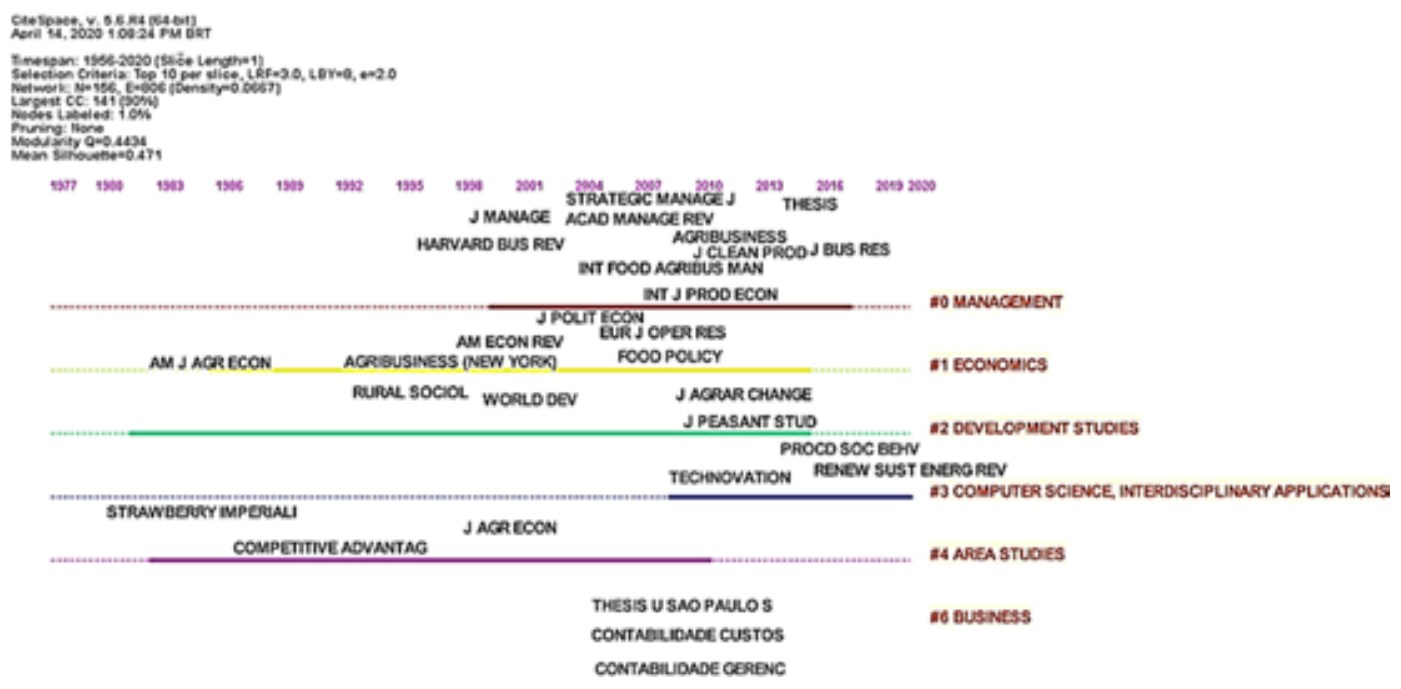

FIGURA 8 - Rede de periódicos citados pelos autores de 787 artigos indexados na base de dados Web of Science, com foco no agronegócio, de 1956 a 2020

Fonte: Elaborado pelos autores (2020)

Organizações Rurais \& Agroindustriais, Lavras, v. 23, e1737, 2021 


\subsection{Agenda de estudos futuros}

Este trabalho, para além das análises já apresentadas, traz uma agenda de estudos futuros (Figura 9). Em especial, são endereçados temas fortuitos, relacionados ao agronegócio, e que têm sido mencionados na literatura recente. Através do framework, é possível identificar os temas abordados pelos artigos mais citados a partir de 2018.

Dentre as publicações mais citadas, se destacam Martins e Lucato (2018), Ribeiro e dos Santos Coelho (2020), Pierri (2020) e Aguiar et al., (2020) que contextualizam pesquisas direcionadas às políticas públicas em que governos ou órgãos públicos agem direta ou indiretamente no contexto do agronegócio, além de abordarem os fatores econômicos, como transações financeiras e representatividade sobre o produto interno bruto de países. O cooperativismo também é abordado em sua dinâmica local e nos processos de seus agentes que estão ligados ao tema. As relações de risco na demanda da cadeia produtiva do agronegócio possuem algumas frentes de análise a serem abordadas, e podem estar relacionadas a diversas áreas da ciência (BEHZADI et al., 2018a; 2018b; PUCHALSKY et al., 2018).

\begin{tabular}{|c|c|}
\hline Tema & Publicações" \\
\hline $\begin{array}{c}\text { Riscos de } \\
\text { gerenciamento da } \\
\text { cadeia produtiva do } \\
\text { agronegócio } \\
\end{array}$ & $\begin{array}{l}\text { Behzadi, et al. (2018a; } \\
\text { 2018b); Puchalsky, et al. } \\
\text { (2018) }\end{array}$ \\
\hline $\begin{array}{c}\text { Efeitos da responsa- } \\
\text { bilidade social corpo- } \\
\text { rativa no desempenho } \\
\text { do agronegócio } \\
\end{array}$ & Penalver, et al. (2018) \\
\hline $\begin{array}{c}\text { Analisar as relaçð̃es } \\
\text { comerciais entre } \\
\text { paises no agronegócio }\end{array}$ & $\begin{array}{c}\text { Oliveira (2018); Oliveira } \\
\text { (2019); Arbeletche } \\
\text { (2020) }\end{array}$ \\
\hline $\begin{array}{c}\text { Riscos de } \\
\text { gerenciamento da } \\
\text { cadeia produtiva do } \\
\text { agronegócio } \\
\end{array}$ & $\begin{array}{l}\text { Behzadi, et al. (2018a; } \\
\text { 2018b); Puchalsky, et al. } \\
\text { (2018) }\end{array}$ \\
\hline $\begin{array}{l}\text { Relaçð̄es sociais, } \\
\text { biotecnologia, } \\
\text { biofisica, } \\
\text { biodiversidade e } \\
\text { ecoinovação }\end{array}$ & $\begin{array}{c}\text { Panez-Pinto, Mansilla - } \\
\text { Quinones e Moreira- } \\
\text { Muñoz (2018); Ben } \\
\text { Amara, Chen e Hafee } \\
\text { (2020); Salvini et al. } \\
\text { (2018) } \\
\end{array}$ \\
\hline $\begin{array}{l}\text { Politicas e fatores } \\
\text { econômicos ligados } \\
\text { ao agronegócio }\end{array}$ & $\begin{array}{c}\text { Aguiar et al., (2020); } \\
\text { Pierri (2020); Ribeiro } \\
\text { Coelho (2020); Riaz e } \\
\text { Hashmi (2019); } \\
\text { Mendieta et al. (2020); } \\
\text { Martins e Lucato (2018) } \\
\end{array}$ \\
\hline $\begin{array}{c}\text { Aspectos da } \\
\text { Tecnologia na gestão } \\
\text { do agronegócio }\end{array}$ & Chege e Wang (2020) \\
\hline $\begin{array}{c}\text { Midias sociais nas } \\
\text { marcas, imagem e } \\
\text { posicionamento do } \\
\text { agronegócio }\end{array}$ & $\begin{array}{c}\text { Carpio, Fermandez e } \\
\text { Urbano (2020) }\end{array}$ \\
\hline
\end{tabular}

Agenda de pesquisas

Estudos sobre a perecibilidade no planejamento das cadeias de suprimentos do agronegócio em cenários cada vez mais complexos.

Modelagem da resiliência da cadeia de suprimentos do agronegócio por meio de medidas como: tempo de recuperaçăo (TTR) na funçào objetivo e reexaminar a eficácia das estratégias de gerenciamento de riscos.

Pesquisas mais profundas sobre métodos distintos de treinamento para previsão de séries temporais no agronegócio, a fim de se apurar o melhor método de otimização para cada caso, buscando o melhor conjunto de parâmetros que aprimore os resultados da previsẫo.

Analisar as relações comerciais no agronegócio entre Brasil e outros paises.

Estudos sobre a internupçào, tanto do lado da demanda como da oferta.

Pesquisas que reflitam sobre a heterogeneidade existente no agronegócio abrangendo as relaçð̄es sociais, biodiversidade, a biotecnologia, as culturas, ecologia, inovações, biofísica (solos, clima, hidrologia), indústrias, agriculta familiar.

Os efeitos da tecnologia na cadeia do agronegócio e os impactos nas políticas públicas, economia, sociedade e meio ambiente.

As ferramentas de marketing e suas aplicações nos estudos sobre mercado, consumo e marcas.

Estudar os efeitos da responsabilidade social corporativa (RSE) indireta e direta no desempenho do agronegócio.

FIGURA 9 - Framework de sugestões para pesquisas futuras sobre o agronegócio

*Estudos quantitativos e/ou qualitativos que utilizaram técnicas de coleta/análise de dados tais como regressões lineares, equações estruturais, entrevistas, econometria e teste de hipóteses.

Fonte: Elaborado pelos autores (2020)

Organizações Rurais \& Agroindustriais, Lavras, v. 23, e1737, 2021 
Conforme mostra a Figura 8, várias são as áreas do agronegócio que ainda necessitam de mais estudos. Os resultados indicaram que pesquisas ligadas ao planejamento e à perecibilidade podem ser instrumentos valiosos para que se possam desenvolver sistemas gerenciais mais eficientes no agronegócio. Além disso, outros fatores que influenciem na cadeia de suprimentos podem ser necessários para que se identifique as fragilidades do agronegócio, bem como as principais interfaces do setor que, eventualmente, estejam sendo pouco estudadas. Além disso, análises de séries temporais parecem ser pesquisas cabíveis e necessárias para o aprofundamento do conhecimento científico. Análises ligadas a essas condições (perecibilidade, planejamento, cadeias produtivas e séries temporais) podem ser importantes instrumentos que venham a fortalecer o agronegócio e contribuir com o desenvolvimento de uma gestão mais estratégica, com vistas para o longo prazo.

Outro aspecto relevante e que merece atenção são as relações de comercialização. É possível que o agronegócio tenha diversas áreas com problemas de comercialização, condição que ajuda a explicar a necessidade de mais pesquisas sobre esse tema. Além disso, de que forma a utilização de tecnologias podem contribuir com o desenvolvimento do agronegócio é outra questão que merece muitos estudos para que seja possível investigar como tem sido o desenvolvimento tecnológico do agronegócio, com especial destaque para a eficiência de propriedades rurais.

Tais iterações são importantes pois, conforme salientam Lopes et al. (2016), muitas propriedades rurais ainda possuem baixas eficiências econômicas, técnicas e gerenciais no Brasil. Ademais, é necessário que se preze também por pesquisas que venham de encontro com a responsabilidade social no agronegócio, visto que seja um tema emergente e que ainda necessita de mais estudos que contribuam com o entendimento de como todos os elos da cadeia de suprimentos do agronegócio se articulam em prol da responsabilidade social.

Os temas de pesquisa relações sociais, biotecnologia, biofísica, biodiversidade, ecoinovação também foram representativos em sua abordagem perante o agronegócio e suas relações políticas, econômicas e sociais. A demanda da sociedade por inovações, por preocupações sustentáveis que sejam realmente acessíveis e assertivas, pela preocupação com o meio ambiente e a responsabilidade social dos stakeholders do agronegócio local e global se tornou foco de estudos nesta perspectiva investigativa (PINTO; QUIÑONES; MUÑOZ, 2018; SALVINI et al., 2018; OLIVEIRA, 2019; AMARA; CHEN; HAFEE, 2020; ARBELETCHE, 2020).
A comunidade acadêmica interessada pode se beneficiar dessa agenda de pesquisa, ao direcionar, sobretudo, estudos empíricos, às lacunas levantadas. Neste sentido, novos horizontes de pesquisas poderão ser conduzidas e atingir resultados ainda mais promissores a respeito do agronegócio local ou global.

\section{CONSIDERAÇÕES FINAIS}

Este trabalho objetivou investigar o comportamento da literatura científica internacional sobre o agronegócio, a fim de poder pautar os temas que estão emergindo dentro do segmento. Neste sentido, procurou-se evidenciar as tendências pertinentes as publicações nesse campo, os periódicos e autores mais relevantes, os principais países de origem, as categorias de publicação, as estruturas de cocitação e coautoria dos mesmos, além da discussão acerca dos principais trabalhos mais citados, e com maior relevância para o tema. Ao longo do artigo, conseguiu-se levantar esses dados com êxito. De forma adicional, foi sugerida uma agenda de pesquisa futura, em que pesquisadores interessados no tema podem se basear para direcionar trabalhos empíricos.

Por meio dos resultados obtidos, foi possível responder às perguntas que direcionaram esta pesquisa e apontar que, cada vez mais, o agronegócio vem sendo estudado de maneira plural em termos disciplinares e temáticos. Isso sugere que a ideia do agronegócio, sustentada pela imagem de rede, está cada vez menos condicionada à agricultura de maneira isolada e, cada vez mais, à sua cadeia.

Esse aspecto identificado permite endereçar pesquisas (concernentes ao agronegócio) relacionadas ao risco da cadeia produtiva, responsabilidade social corporativa, relações comerciais entre países, relações sociais, políticas públicas, fatores econômicos, cooperativismo, tecnologia, mídias sociais e posicionamento de marca. Adicionalmente, estudos recentes têm demonstrado a dinâmica e a complexidade do agronegócio, o que sugere que análises mais amplas poderiam ser úteis. Para tal, estudos quantitativos (como econometrias, por exemplo) e qualitativos (como estudos multicaso com entrevistas em profundidade) podem ser utilizados para se compreender melhor essa dinâmica.

A presente pesquisa apresentou algumas limitações que interferem no entendimento mais aprofundado da comunidade científica sobre o tema. Embora a base de dados Web of Science seja uma das mais maiores em todo o mundo, pesquisas em outras bases podem evidenciar novas perspectivas para o agronegócio. Além disso, 
por ser uma base dados majoritariamente internacional, a Web of Science não consegue capturar muitos artigos publicados no Brasil, por exemplo, para investigar características do agronegócio brasileiro e suas interfaces com o agronegócio internacional.

Finalmente, em decorrências das limitações metodológicas, sugerem-se outros estudos bibliográficos, tais como revisões sistemáticas ou integrativas, com intuito de aprofundar os dados e informações, garantindo ainda mais relevância e contextualização para as discussões a serem realizadas. Ainda, o trabalho poderia ser ampliado ao utilizar outras strings de busca, como também de outras bases de dados, que não somente a Web of Science.

\section{AGRADECIMENTOS}

Agradecimento à Coordenação de Aperfeiçoamento de Pessoal de Nível Superior (CAPES) e ao Conselho Nacional de Desenvolvimento Científico e Tecnológico (CNPq) pelo apoio financeiro, e à Universidade Federal de Lavras (UFLA) e à Escola Superior de Propaganda e Marketing (ESPM) por proporcionarem a realização deste estudo.

\section{REFERÊNCIAS}

Aguiar, L. G., et al. (2020). Network cooperatives and the reduction of opportunism in the agribusiness segment: a systematic bibliographic review. Independent journal of management \& production, 11(1).

Amanor, K.S. (2012). Global resource grabs, agribusiness concentration and the smallholder: two West African case studies. Journal of Peasant Studies, 39(3-4), 731-49.

Amara, D. B.; Chen, H.; Hafeez, M. (2020). Role of entrepreneurial opportunity identification factors in the eco-innovation of agribusiness. Business Strategy \& Development.

Arbeletche, P. (2020). O agronegócio no Uruguai: evolução e estratégias cambiantes no símbolo XXI. RIVAR (Santiago), 7(19), 109-129.

Barros, G. S. C., et al. (2020). Boletim Mercado de Trabalho do Agronegócio Brasileiro. Centro De Estudos Avançados Em Economia Aplicada (Cepea) e Fundação De Estudos Agrários Luiz De Queiroz (Fealq), (4), Piracicaba.
Behzadi, G., O’Sullivan, M. J., Olsen, T. L.; Zhang, A. (2018a). Agribusiness supply chain risk management: A review of quantitative decision models. Omega, 79, 21-42.

Behzadi, G., O’Sullivan, M. J., Olsen, T. L.; Zhang, A. (2018b). Allocation flexibility for agribusiness supply chains under market demand disruption. International Journal of Production Research, 56(10), 3524-3546.

Boehlje, Michael. (1999). Structural changes in the agricultural industries: how do we measure, analyze and understand them?. American Journal of Agricultural Economics, 81(5), 1028-1041.

Bornmann, L.; Mutz, R. (2015). Growth rates of modern science: A bibliometric analysis based on the number of publications and cited references. Association for Information Science and Technology, 66(11), 2215-2222.

Cáceres, D. M. (2014). Accumulation by Dispossession and Socio-Environmental Conflicts Caused by the Expansion of Agribusiness in Argentina. Journal of Agrarian Change, 15(1), 116-147.

Chege, Samwel Macharia; Wang, Daoping. (2020). The impact of technology transfer on agribusiness performance in Kenya. Technology Analysis \& Strategic Management, 32(3), 332-348.

Chen, C. (2006). CiteSpace II: Detecting and visualizing emerging trends and transient patterns in scientific literature. Journal of the American Society for information Science and Technology, 57(3), 359-377.

Cook, M. L.; Chaddad, F. R. (2000). Agroindustrialization of the global agrifood economy: bridging development economics and agribusiness research. Agricultural Economics, 23, 207-218.

Da Silva, J. P. N.; De Oliveira, C. C.; Garcia, A. S. (2019). A dinâmica dos modelos de negócios para o agronegócio: uma visão bibliométrica de 1956 a 2017 pela Web of Science. Extensão Rural, 26(4), 23-38.

Davis, J. H. (1956). From agriculture to agribusiness. Harvard Business Review, 34, 107-115. 
Davis, J. H.; Goldberg, R. A. (1957). A concept of agribusiness. In Division of Research. Graduate School of Business Administration, Boston, Harvard University.

Candido, E. de S., et al. (2014). The use of versatile plant antimicrobial peptides in agribusiness and human health. Peptides, 55, 65-78.

Carpio, Deiyalí A., Fernandez, Alberta, Urbano, Beatriz. (2020). How to gain image and positioning on social media: Spanish agribusiness firm image and position on social media. Applied Economics, 52(21), 2280-2291.

Duque, P., Cervantes, L. S. C. (2019). Responsabilidad Social Universitaria: una revisión sistemática y análisis bibliométrico. Estud. Gerenc., 35(153), 451-464.

Embrapa. (2018). Visão 2030: o futuro da agricultura brasileira (Embrapa), Brasília, DF.

Gil, A. C. (2002). Como classificar pesquisas, 4 (Atlas), São Paulo.

Gorenstein, S. (1998). Sector agroalimentario: las relaciones industria/gran distribución. Desarrollo Económico, 38(149), 457.

Hamilton, S. (2016). Revisiting the History of Agribusiness. Business History Review, 90(3), 541-545.

Heredia, B., Palmeira, M., Leite, S. P. (2010). Sociedade e Economia do "Agronegócio" no Brasil. Revista Brasileira de Ciências Sociais, 25(74), 159-176.

Lizot, M., et al. (2016). Gestão de custos no agronegócio: aplicação de uma metodologia bibliométrica em periódicos de alto fator de impacto. Custos e @gronegócio on line, 85503,390 .

Lusk, J. L., Hudson, D. (2004). Willingness-to-Pay Estimates and Their Relevance to Agribusiness Decision Making. Review of Agricultural Economics, 26(2), 152169.

Lopes, M. A., et al. (2016). Uso de ferramentas de gestão na atividade leiteira: um estudo de caso no sul de Minas Gerais. Revista Científica de Produção Animal, 18(1), 26-44.
Macedo, M. A. da S., Lunga, A. (2010). Bibliometric and critical mapping of the economical and financial viability analysis of agribusiness projects: an evaluation of the publication in the sober congress in the period 20062009. Custose@gronegócio on line, 6(2),67-88.

Martins, F. S., Lucato, W. C. (2018). Structural production factors' impact on the financial performance of agribusiness cooperatives in Brazil. International Journal of Operations \& Production Management, 38(3), 606-635.

Mendieta, O., et al. (2020). Synergistic effect of sugarcane scum as an accelerant co-substrate on anaerobic codigestion with agricultural crop residues from noncentrifugal cane sugar agribusiness sector. Bioresource technology, 303, Article 122957.

Oliveira, G. L. T. (2019). Boosters, brokers, bureaucrats and businessmen: Assembling Chinese capital with Brazilian agribusiness. Territory, Politics, Governance, 7(1), 22-41.

Peñalver, Antonio Juan Brioñes, et al. (2018). Analysis of corporate social responsibility in Spanish agribusiness and its influence on innovation and performance. Corporate Social Responsibility and Environmental Management, 25(2), 182-193.

Pereira, C. N., De Castro, C. N. (2017). O Sistema Nacional de Pesquisa Agropecuária: histórico, estrutura e financiamento. Texto para Discussão.

Pierri, J. (2020). Resultados económicos del agronegocio en la producción de granos en Argentina en el marco de las políticas públicas (1990-2017). RIVAR, 7(19), 88-108.

Pinto, A. P., Quiñones, P. M., Muñoz, A. M. (2018). Agua, tierra y fractura sociometabólica del agronegocio. Actividad frutícola en Petorca, Chile. Bitácora Urbano Territorial, 28(3), 153-160.

Prado, J. W., et al. (2016). Multivariate analysis of credit risk and bankruptcy research data: a bibliometric study involving different knowledge fields (1968-2014). Scientometrics, 106(3), 1007-1029.

Puchalsky, W., et al. (2018). Agribusiness time series forecasting using Wavelet neural networks and metaheuristic optimization: An analysis of the soybean sack price and perishable products demand. International Journal of Production Economics, 203, 174-189.

Organizações Rurais \& Agroindustriais, Lavras, v. 23, e1737, 2021 
Riaz, Muhammad, Hashmi, Masooma Raza. (2019). MAGDM for agribusiness in the environment of various cubic m-polar fuzzy averaging aggregation operators. Journal of Intelligent \& Fuzzy Systems, 37(3), 3671-3691.

Ribeiro, M. H. D. M., Dos Santos Coelho, L. (2020). Ensemble approach based on bagging, boosting and stacking for short-term prediction in agribusiness time series. Applied Soft Computing, 86, Article 105837.

Salvani, G., et al. (2018). Roles and drivers of agribusiness shaping Climate-Smart Landscapes: A review. Sustainable Development.

Sutter, P. S. (2013). The world with us: the state of American environmental history. The Journal of American History, 100(1), 94-119.

USDA. (2020). World Agricultural Production. United States Department of Agriculture. Circular Series WAP 4-20 April 2020. https://bit.ly/2CYoKpH
. (2018). What is agriculture's share of the overall U.S. economy? United States Department of Agriculture. https://bit.ly/2Lkp6b0

Wang, Qi, Waltman, Ludo. (2016). Large-scale analysis of the accuracy of the journal classification systems of Web of Science and Scopus. Journal of Informetrics, 10(2), 347-364.

World Bank. The World Bank. https://www.worldbank. org/

Zhang, Q. F., Donaldson J. A. (2008). The Rise of Agrarian Capitalism with Chinese Characteristics: Agricultural Modernization, Agribusiness and Collective Land Rights. The China Journal, (60), 25-47.

Zylbersztajn, D. (2017). Agribusiness systems analysis: origin, evolution and research perspectives. Rev. Adm., 52(1), 114-117. 